\title{
O cinema entre 0 real e o imaginário
}

\section{Rogério de Almeida}

"Falam por mim os que estavam sujos de tristeza e feroz desgosto de tudo, que entraram no cinema com a aflição de ratos fugindo da vida, são duras horas de anestesia, ouçamos um pouco de música, visitemos no escuro as imagens - e te descobriram e salvaram-se."

(Carlos Drummond de Andrade, "Canto ao homem do povo Charles Chaplin")

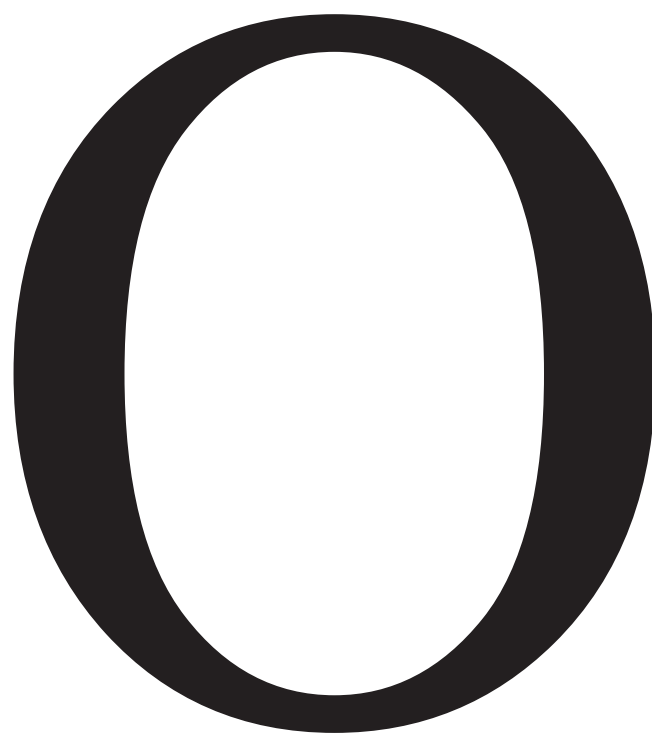

cineasta Raúl Ruiz (2000, p. 86) idealizou fazer um filme que giraria em torno de uma aposta entre Georges Méliès e os irmãos Lumière. Teriam de filmar $A$ volta ao mundo em 80 dias, de Júlio Verne, a tempo de exibi-lo na Exposição Universal de 1900, em Paris. Para isso, teriam 80 dias de prazo. Como fariam seus filmes?

Este artigo resulta de auxílio à pesquisa concedido pela Fapesp, Projeto 19/00649-6.

ROGÉRIO DE ALMEIDA é professor associado da Faculdade de Educação da USP, coordenador do Lab_Arte e autor de, entre outros, O imaginário trágico de Machado de Assis (disponível no Portal de Livros Abertos da USP). 
Os irmãos Lumière embarcariam com seu cinematógrafo em trens e navios e filmariam a viagem, enquanto Georges Méliès ficaria em Paris, valendo-se de todos os truques e efeitos especiais possíveis para recriar o mundo dentro do estúdio.

Embora o filme não tenha sido feito, a aposta em questão põe em evidência que o cinematógrafo, como foi batizado por seus criadores, poderia, desde o início, registrar regimes diferentes da realidade, um documental e outro ficcional.

O cinematógrafo dos Lumière botou fim à corrida tecnológica a que diversos inventores haviam se lançado para a criação de um dispositivo capaz de gravar e reproduzir imagens em movimento, passo inevitável depois da invenção da máquina fotográfica, décadas antes, embora nada nos impeça de supor, como fez Morin (2014), que o sonho do duplo já povoasse a mente de nossos ancestrais habitantes pré-históricos das cavernas, em cujas paredes pintavam não meras imagens, mas narrativas, organizadas temporalmente como sucessão de acontecimentos.

Os primeiros filmes rodados pelos irmãos Lumière estavam limitados ao registro de um minuto, gravados por uma câmera imóvel, sustentada por um tripé, e geralmente apontada para uma cena do cotidiano: a saída de operários da fábrica, o trem que chega à estação ou um jardineiro que tem problemas com a mangueira. Embora tenham sido filmados em grande profusão - há mais de 130 registros e exibidos em feiras, circos e vaudevilles, não sem grande espanto e curiosidade da plateia, os criadores do cinematógrafo não acreditavam no futuro de sua invenção.

Por essa razão, recusaram-se a vender um exemplar para Georges Méliès, que, para realizar seus filmes, teve de adquirir na In- glaterra o animatógrafo, aparelho semelhante desenvolvido por Robert Paul. Seus filmes incorporaram elementos do ilusionismo, por meio de trucagens, e das féeries, gênero teatral caracterizado pelo fantástico.

Tendo em vista as primeiras produções fílmicas, a partir das experiências dos Lumière e de Méliès, constata-se que o cinema, desde seus primórdios, assume dois modelos de fabricação e registro de imagens: o documental, cuja principal característica é reportar um acontecimento real, e o ficcional, que narra uma determinada história, real ou inventada, mas sobretudo encenada, ou seja, planejada, preparada, roteirizada antes da filmagem.

Esses dois modelos de cinema, o documental e o ficcional, remetem, por sua vez, a uma longa tradição cultural, cujo ápice remonta à Grécia Antiga, com Homero e Heródoto dividindo - apesar dos três séculos que os separam - a encarnação da ficção e da História. O primeiro, reunião dos aedos que o antecederam, organiza as experiências humanas em narrativas ficcionais, brotadas da imaginação, enquanto o segundo registra as ações humanas que factualmente teriam acontecido.

O que está em jogo nesse paralelo é o reconhecimento da oposição entre dois regimes de representação da realidade: um que seria verdadeiro e outro fabuloso; um que registra fatos reais e outro que inventa ficções. A verdade, de um lado; a fantasia, de outro. $\mathrm{Ou}$, em termos mais filosóficos: num polo, a razão; no outro, a imaginação.

Embora sejam duas modalidades distintas de construção da realidade, as quais poderiam conviver em igual grau de valorização - no sentido de que avaliam a realidade e a ela conferem valor (Nietzsche, 1983; Deleuze, 1976) -, historicamente uma se sobrepõe à ou- 
tra e reivindica para si a supremacia no trato com o real, desvalorizando as demais formas simbólicas de conhecimento (Cassirer, 1994).

A crítica ao modo como a racionalidade impõe-se na disputa pela hegemonia da verdade e, consequentemente, pela legitimidade das narrativas sobre a realidade difunde-se há um bom tempo, como nas críticas à razão instrumental ou à técnica, como nos questionamentos epistemológicos e paradigmáticos das ciências, como nas discussões pós-modernas etc. De certa forma, são desdobramentos do que Nietzsche (1983) detectou como niilismo, isto é, a desvalorização dos valores supremos, a morte de deus, a constatação da impossibilidade de responder racionalmente às perguntas "por quê?" e "para quê?", que estão na base do nascimento da filosofia grega (Giacoia Junior, 2014). Essa crítica ao domínio da verdade pela razão (que engloba tanto investidas filosóficas quanto científicas) teve como estratégia de combate o iconoclasmo.

A iconoclastia estaria no cerne da história ocidental, de acordo com a perspectiva de Gilbert Durand (1994), como execração das imagens e, sobretudo, de seu caráter cognoscente, simbólico e hermenêutico. À imagem obstrui-se sua potencialidade de expressar conhecimentos para reduzi-la à aparição sensível - e, portanto, enganadora - da superfície. Enquanto a razão marchava imperiosa sobre o reino do inteligível, a imaginação chafurdava no caos informe das sensações.

Essa lógica iconoclasta pressupõe uma divisão hierárquica entre os domínios da realidade e da representação. A razão torna-se, então, o meio de validação da verdade, caminho único de acesso ao que é real. E ao proceder assim submete a imaginação a um papel secundário, que eventualmente, sob certas condições, até pode representar a realidade, mas jamais seria real ou teria qualquer autoridade sobre o real. A imagem seria um índice de remissão ou, como se consolidou na tradição filosófica, a representação mental de um objeto ausente (Abbagnano, 2007).

Contra o iconoclasmo, o imaginário se ressignifica no século XX amparado por uma série de estudos, muitos deles vinculados ao Círculo de Eranos, que congregava pensadores como Rudolf Otto, Carl Gustav Jung, Joseph Campbell, Mircea Eliade e Gilbert Durand. Essa revalorização do imaginário o desloca do posto passivo de representação para a condição ativa de mediador. $\mathrm{O}$ imaginário, então, é o que organiza o real (Durand, 1997). O conhecimento da realidade deixa de ser a enunciação totalizante da verdade, operada pela razão, para se tornar a expressão figurativa de uma perspectiva, mediada pela interpretação.

Como perspectiva, o conhecimento se mostra parcial e dependente do ponto de vista - é o que define o perspectivismo nietzschiano: "apenas uma visão perspectiva, apena um 'conhecer' perspectivo" (Nietzsche, 1998, p. 109). Como expressão figurativa, assenta-se numa formulação que tem a imagem como base, cujo a priori é o sentido (ainda que de uma ausência de sentido). Como interpretação, requer uma hermenêutica, compreendida como uma estratégia filosófica que visa a compreender, traduzir o sentido de uma obra.

Voltando ao cinema, e mais especificamente às primeiras imagens em movimento produzidas por Louis e Auguste Lumière, o que se observa não é o registro imparcial e neutro da realidade, mas a organização premeditada do espaço, o controle do tem- 
po e a perspectivação do olhar. É o que mostra Thierry Frémaux, em seu documentário Lumière! A aventura começa (2016), ao analisar as primeiras filmagens e constatar que os irmãos inventores preparavam as cenas antes de registrá-las. Por exemplo, o famoso A saída dos operários da fábrica Lumière (1895) não foi resultado de uma única tomada, mas de três, inclusive numa delas sai da fábrica também uma carroça; há também uma certa ordenação no modo como os operários saem, o que permite supor algum tipo de orientação para o registro da cena. O regador regado, do mesmo ano, é menos um registro documental que a encenação de uma gag, na qual um menino pisa na mangueira do jardineiro interrompendo o fluxo da água para depois, quando o regador olhar para a ponta da mangueira, molhá-lo. O que se observa é que o jardineiro, após apanhar o menino, retorna ao quadro para castigá-lo à frente dos espectadores. Em $O$ almoço do bebê é evidente a composição da mesa e a encenação do casal, assim como em Les forgerons (1895), em que o "trabalhador" usa camisa branca e gravata e ao final da cena recebe uma bebida, em pleno "horário de trabalho".

$\mathrm{O}$ que esses primeiros filmes mostram é a preocupação do cinematografista em compor a cena nos limites do quadro, organizando antecipadamente o espaço a ser filmado, do primeiro plano à profundidade de campo. Além disso, como o rolo só registrava algo em torno de 60 segundos, deduz-se que havia uma premeditação das ações de modo a caberem no tempo e, por fim, a escolha cuidadosa da perspectiva, do ponto de vista do lugar em que a câmera seria instalada. Portanto, as primeiras realidades captadas pelo cinematógrafo, por mais reais que pu- dessem ser, nunca deixaram de expressar uma certa manipulação estética, nunca negligenciaram os efeitos que poderiam causar no espectador ou, em outras positivas, sempre compreenderam o caráter imaginário que dota de sentido a realidade.

A separação radical entre realidade e imaginário - matriz da oposição entre verdade e ficção - e sua consequente hierarquização dos saberes no domínio do que é real e verdadeiro não se sustenta mais no mundo contemporâneo. Nem religião, nem filosofia, nem ciência - tal como foram institucionalizadas - têm sua legitimidade assegurada. Não significa que desapareceram ou deixaram de ter relevância, mas que perderam e continuam perdendo território, ainda mais no cenário atual de avanço do niilismo, do negacionismo e da ampliação de circulação de mentiras, chamadas de fake news.

O problema não é apenas a cisão entre real e imaginário e sua definição de quais discursos estariam aptos a apresentar a verdade do mundo e quais se limitariam a fictícia ou ficcionalmente representá-lo, mas seus efeitos imprevistos, entre os quais a disseminação da mentira e a negação de fatos históricos ou dados científicos. O que se tornou patente é que as pretensas verdades, obtidas pelo uso da razão, como na filosofia e nas ciências, nunca deixaram de se manifestar como imaginário, pois é efetivamente o imaginário que organiza os discursos, sejam eles filosóficos, científicos, literários ou ficcionais. Embora sejam imaginários distintos, com normas particulares - por exemplo, a ciência para ser ciência depende de um imaginário metodológico, que envolve procedimentos, medições, validações, análises, provas, contraprovas etc. -, os discursos sobre o mundo, como formas simbólicas de 
conhecimento (Cassirer, 1994), respondem a uma gramática, preservam regras, são jogos de linguagem (Wittgenstein, 1999). Como textos (urdidura de sentidos), manifestam-se em determinados contextos dados.

Assim, um conto, um romance, um filme ou uma peça de teatro não são mentira, mas se relacionam com o real - seja para expressá-lo ou iludi-lo - de maneira ficcional, por meio de um jogo simbólico que responde a um determinado imaginário. Já um tratado filosófico, uma teoria científica ou uma equação matemática também não são "a" verdade (isso não quer dizer que sejam mentira), relacionando-se com o real por meio de outras regras simbólicas, que envolvem, por exemplo, o conceito e a lógica, mas que não deixam de organizar imaginariamente o mundo concreto.

Isto posto, é preciso desfazer dois equívocos: o primeiro, que o real se opõe ao imaginário; e o segundo, que a verdade se opõe à ficção. O que se opõe ao real é a ilusão, do mesmo modo que é a mentira que se opõe à verdade. Para investigar essa questão e resgatar a importância do imaginário e da ficção no diálogo com o real, serão analisados os pares real-ilusão e verdade-mentira.

Sobre o real e a ilusão: embora seja muito difícil definir o que é o real, uma vez que o real escapa às tentativas de apreendê-lo por meio de enunciados, imagens, fórmulas, teorias, etc., podemos nos valer de uma aproximação provisória, mais geral, a partir dos estudos do filósofo Clément Rosset (1989, 2004, 2008), que trata o real como aquilo que não possui duplo, que é único, singular, ou mesmo idiota, no sentido grego do termo, “aquilo que é único”, insignificante, por não ter nenhum significado em si; portanto, o real é a dimensão da existência "que não é interpretável". Em uma palavra, "o real é" (cf. Almeida, 2019).

Já a ilusão é um mecanismo de proteção que impede justamente a compreensão do real. Na ilusão, não se nega o real em sua totalidade, mas se esconde sua parte desagradável, vira-se o rosto, olha-se para outro lugar, ignora-se o que foi percebido. A estratégia mais corrente da ilusão é valer-se do duplo. A noção de duplo "implica nela mesma um paradoxo: ser ao mesmo tempo ela própria e outra” (Rosset, 1998, p. 24), isso porque o real não deixa de ser real, mas a ele é acrescida outra realidade, que ocupa seu lugar, ainda que de maneira ilusória. Desse modo, o mecanismo da ilusão opera não pela negação total do real, mas pela negação da parte desagradável, que é substituída por um duplo.

Matrix (1999), de The Wachowskis, é um bom exemplo. A nossa realidade é transformada num duplo da verdadeira realidade, que seria a de um mundo tenebroso em que as pessoas sobreviveriam acopladas a máquinas para fornecer energia. Assim, o mundo onde acreditamos viver não passaria de uma realidade virtual, projetada em nossos cérebros. A similitude com o modelo platônico do mundo das ideias em oposição ao mundo sensível, ou do mundo cristão com o reino dos céus e a vida terrena, não é fortuita, assim como a recente analogia entre corpo-hardware e mente-software não é estranha à concepção cartesiana de corpo como máquina em contraste com o espírito eterno.

Outro par a ser avaliado é o da verdade e mentira. Em primeiro lugar, é preciso não tomar a ilusão por mentira. A mentira é geralmente a inversão de um dado considerado verdadeiro e tem um uso intencional. Equivocar-se com uma informação não é 
necessariamente mentir, pois para mentir é preciso saber a verdade e ocultá-la. O sujeito mentiroso tem em mente duas informações paralelas. A que ele sabe correta e a outra que ele coloca em seu lugar. Os detectores de mentira, embora não sejam confiáveis, captariam esse "excesso" de energia dispendido pelo corpo, que necessita simultaneamente pensar no que se diz e no que se oculta. Por isso, a mentira é intencional, enquanto o engano é involuntário.

Estabelecidas essas diferenças, podemos retornar ao imaginário para entender que ele se relaciona tanto com o real quanto com a ilusão. O imaginário pode, assim, produzir imagens, discursos, sentidos que afirmem o real, que confirmem a realidade do que existe, assim como também pode produzir imagens, discursos, sentidos que sejam ilusórios, que neguem a realidade ou sua parte desagradável. O imaginário responde tanto pelos fantasmas, monstros e pesadelos quanto pelos pensamentos, discursos e devaneios. Isso porque, de acordo com Cassirer (1994), o homem é um animal symbolicum, isto é, opera uma mediação simbólica no trato com o mundo, com o outro e consigo mesmo. Assim, linguagem, ciência, religião e arte são formas simbólicas, mediações sem as quais não nos situaríamos no mundo.

O imaginário não é uma válvula de escape, uma fuga da vida, subterfúgio ou estratagema de evasão, mas modalidade de trato, de lida com o real, principalmente por meio de sua função eufemizadora. Para Gilbert Durand (1988, p. 121),

"a função da imaginação é antes de mais nada uma função de eufemização, não um simples ópio negativo, máscara que a consciência ergue face à horrenda figura da morte, mas pelo contrário, dinamismo prospectivo que, através de todas as estruturas do projeto imaginário, tenta melhorar a situação do homem no mundo".

Por outras palavras, é a mesma constatação de George Steiner (2003, p. 14): “[...] só o homem, a princípio, possuiria os meios para alterar seu mundo recorrendo a cláusulas condicionais hipotéticas". O imaginário põe em jogo as possibilidades: "e se fosse assim?", "e se fizéssemos de outro modo?", "e se olharmos por outra perspectiva?".

Essas cláusulas condicionais hipotéticas nos lembram que o futuro, como tempo ainda não vivido, não é materialidade concreta, mas um efeito produzido pela linguagem, e mais especificamente pelo tempo verbal. Contudo se, como linguagem, o futuro depende da imaginação, a compreensão da linguagem como um todo depende cognitivamente de operações de tradução: "Entre línguas ou no interior de uma língua, a comunicação humana é igual à tradução" (Steiner, 2005, p. 72). De modo mais geral, compreender é traduzir, não somente nos casos em que se verte de uma língua para outra, mas no interior da própria língua, quando traduzimos um termo por outro, ou ainda nos casos de tradução intersemiótica, em que interpretamos "signos verbais por meio de sistemas de signos não verbais" (Jakobson, 2003, p. 65) e vice-versa. É por isso que "leitura e interpretação são, em última análise, 'tradução’ que dá vida, que empresta vida à obra gelada, morta" (Durand, 1998, p. 252).

O imaginário, portanto, não é mero reflexo da realidade, mas seu agente transformador, pois preconcebe objetos, arquiteturas, artes, técnicas, pensamentos, ideologias, interpretações, perspectivas, etc. Se o real 
é o reino do "não interpretável", da insignificância, do vácuo de sentidos, só poderíamos torná-lo pensável, compreensível, interpretável, recorrendo ao imaginário, à tradução desse impensável e indizível em uma imagem simbólica que, por sua redundância e repetição, nos situa nesse reino da singularidade intransponível.

Dessa maneira, a eufemização reforça justamente nossa dependência do imaginário para lidar com o real, de tal modo que não podemos, por ser completamente impossível, separar o real do imaginário. Eufemizar escapa, portanto, à dicotomia da verdade e da mentira, ou da realidade e da ilusão, para se estabelecer justamente no campo da ficção.

Não se pode confundir ficção com mentira. Embora os dicionários a tomem como um de seus sinônimos possíveis, não deveria haver essa opção, uma vez que a ficção não se relaciona nem com a mentira nem com a verdade, mas justamente com a realidade, seja para expressá-la ou eludi-la. Nesse sentido, a ficção funciona como os jogos de linguagem de Wittgenstein (1999), para quem os saberes e sujeitos estão inseridos em jogos que não possuem, por si só, fundamento, mas seguem caminhos imprevisíveis, estão abertos a transformações, ao contingencial, às pressões de outros jogos de linguagem.

Em outras palavras, as ficções articulam, projetam, expressam imaginários, funcionam como um jogo de faz de conta. As crianças, quando brincam de faz de conta, sabem exatamente como produzir ficções para lidar com a realidade. Assim, se uma criança assume o papel de professora e as outras de alunas, passarão a jogar com o imaginário da vida escolar, não para produzi-lo (reino da realidade) ou reproduzi-lo (reino da repetição), mas para expressá-lo, para eufe- mizá-lo, quiçá para significá-lo ou mesmo compreendê-lo. Se nessa situação um adulto tentar se dirigir à criança pelo seu nome próprio, quebrando assim uma das regras do jogo, muito provavelmente a criança o corrigirá dizendo, sem sair da personagem, que ela é a professora. E se o adulto estiver disponível, é bem provável que seja incluído no jogo, talvez para exercer o papel de diretor da escola.

A ficção não quer nos enganar, como no caso da mentira, ocupando o lugar da verdade. Também não quer ser verdadeira, no sentido de uma versão única da realidade, mas promover uma mediação simbólica, organizar imaginariamente o real, ainda que de forma diferente daquela feita pelo pensamento. E isso porque a ficção envolve emoções e sentimentos, enfim, uma participação afetiva:

"Grande parte do valor do sonho, do devaneio e do faz de conta depende fundamentalmente de que a pessoa se considere a si própria como pertencendo a um mundo ficcional. É basicamente enfrentando certas situações, envolvendo-se em certas atividades, tendo ou expressando certos sentimentos, que um sonhador, ou alguém que devaneia ou brinca de faz de conta, entra em acordo com seus sentimentos de fato" (Walton, 2005, p. 136).

No caso de um filme de terror, por exemplo, o medo que o espectador sente diante da tela não é falso ou ilusório, mas também não é o mesmo medo que sentiria em uma situação real, pois se sabe a salvo. Assim, o medo é real, mas controlado, seguro, podendo ser experimentado livremente. É, portanto, um sentimento verdadeiro, mas experimentado por meio de uma situação ficcional. 
A ficção, nessa perspectiva, articula real e imaginário. Como jogo de linguagem, como expressão simbólica, a ficção pode oferecer tanto um modo de proteção do real, por meio da ilusão, por exemplo, quanto meios de afirmá-lo. Mais que isso, a ficção pode borrar suas próprias fronteiras, pode arriscar-se ao blefe, pode subverter expectativas e propiciar experiências de compreensão e tradução da realidade. Vejamos como isso ocorre no cinema.

Swimming pool - na beira da piscina $(2003)^{1}$, de François Ozon, é um bom exemplo, porque o final desestabiliza os alicerces sobre os quais construímos a história. Sarah Morton (Charlotte Rampling) é uma famosa escritora de romances policiais que, cansada de repetir a mesma fórmula literária, decide se isolar na casa de campo de seu editor. Em dado momento, aparece uma bela jovem, que se identifica como filha do editor, Julie (Ludivine Sagnier), e ambas passam a dividir a casa. Certa noite, Julie leva Franck (Jean-Marie Lamour) para casa e se instaura um clima de sedução e ciúme. Apesar de mais velha que Julie, Sarah desperta a atenção de Franck e Julie se irrita. A escritora decide então se retirar. Da varanda de seu quarto, vê o casal à beira da piscina e, enciumada, vai dormir. Como Franck resiste às investidas da jovem, eles se desentendem e ela, num golpe de fúria, acerta sua cabeça e o mata. No dia seguinte, Sarah, ao descobrir o que havia acontecido, decide se aliar a Julie e usa toda sua experiência de romancista para ocultar o cadáver, livrando Julie de qualquer incriminação. A cena final é

1 Baseado em outro filme, La piscine (1969), de Jacques Deray, mas com final completamente diferente. reveladora: depois de um hiato de tempo, vemos Sarah na sala de seu editor, que lhe explica por que não havia gostado de seu manuscrito: não repetia a fórmula que a havia consagrado. A escritora diz que já esperava por essa resposta, razão pela qual publicara seu livro por outra editora. Tira um exemplar de sua bolsa e lhe entrega, sugerindo que o dê de presente à filha. Quando sai do escritório, esbarra numa jovem desconhecida: era a verdadeira Julie, filha de seu editor. É então que nos damos conta de que a Julie retratada no filme não era de fato a Julie da vida real. Somos dessa forma obrigados a reconsiderar toda a história que havíamos construído. O que havíamos assistido não era um acontecimento puramente real, mas a ficção imaginada por Sarah Morton. Entretanto, não era tudo ficção, já que de fato Sarah esteve na casa de campo, onde escrevera o romance.

O interessante dessa experiência estética é que ela nos convida a uma operação cognitiva (Bordwell, 1996) após o término do filme e não somente durante ele, como de costume. E ao rever o filme, ou repassá-lo mentalmente, nos damos conta de que realidade e ficção estão de tal modo entrelaçadas que é impossível separar uma da outra. Mas não é exatamente isso que ocorre na vida, em que somos confrontados por situações em que o real e o imaginário estão de tal forma imbricados que não há como cindi-los?

Do mesmo diretor, François Ozon, Dentro da casa (2012) apresenta o envolvimento de um professor com seu aluno, por meio de suas redações, que narram suas supostas incursões na casa de um colega de classe. As narrativas embaralham ficção e realidade, mas de um modo ainda mais complexo que no filme anterior, pois o professor passa a 
interferir na realidade a partir da ficção que lê. O filme não separa o que é real e ficção, pelo contrário, mostra com clareza como um e outro estão imbricados de maneira indissociável (Almeida, 2016). Aliás, este é um tema recorrente na filmografia de Ozon: Sob $a$ areia (2000) mistura a realidade da morte do marido à ilusão de que ele segue vivo; Frantz (2016), refilmagem de Não matarás (1932), de Ernst Lubitsch, trata da ilusão dos pais que tomam por amigo o assassino de seu filho; $O$ amante duplo (2017) explora os espelhamentos do duplo, ecoando de certa forma a vida dupla de Isabelle (Marine Vacth) em Jovem e bela (2013).

A pele de Vênus (2013), do diretor Roman Polanski, mistura realidade e ficção a partir da audição que um diretor de teatro faz com uma atriz para levar aos palcos uma adaptação do romance $A$ Vênus das peles, de Sacher-Masoch. O que é interessante aqui é que as falas da peça se misturam às falas das personagens do filme, de tal modo que não sabemos se as personagens estão discutindo realmente ou apenas reproduzindo o texto da peça. Na verdade, as duas camadas - a realidade e a ficção - se sobrepõem, de modo que a atriz diz o que ela de fato quer dizer reproduzindo o texto da peça. Novamente, é impossível separar realidade de ficção.

Nenhum outro cineasta, no entanto, foi tão inventivo na defesa da ficção como modo de expressão da realidade como Abbas Kiarostami, que não só as embaralhou, como também aboliu a distinção entre ficção e documentário. Assim, em Close up (1990), assistimos à encenação ficcional de um caso real envolvendo o cineasta Mohsen Makhmalbaf, cuja identidade é usurpada por um golpista, que engana uma família inteira com a promessa de realizar um filme. E a vida continua (1992) e Através das oliveiras (1994) retomam os efeitos do terremoto de Koker, no Irã, encenando e depois reencenando episódios reais.

Outro exemplo é o documentário brasileiro Terra deu, terra come (2010), de Rodrigo Siqueira, que registra o ritual de sepultamento de João Batista, de 120 anos, comandado por Pedro de Almeida, garimpeiro de 81 anos, um dos últimos conhecedores dos vissungos, as cantigas em dialeto banguela cantadas durante os rituais fúnebres. O término do ritual, entretanto, não coincide com o término do filme, que retorna ao ponto inicial do ritual, mas agora com outras tomadas, pelas quais observamos que na realidade não havia nenhum corpo sendo sepultado, mas uma tora de madeira que ocupara seu lugar. A tradição à qual o ritual se filia é em si verdadeira, mas não o que assistimos, puramente encenado. As referências poderiam se multiplicar com os falsos documentários como Zelig (1983), de Woody Allen, ou Borat (2006), de Larry Charles; ou mesmo com as simulações dos shockumentarys como Mondo cane (1962) ou Faces da morte (1979).

Para concluir, falta dizer que a ficção não se limita nem se reduz à expressão do real, mas também possibilita a intensificação da vida por meio da experiência estética. Retornando à epígrafe de Drummond, é o que acontece com os desgostosos que entraram no cinema para fugir da vida e terminaram por encontrá-la. O que fora pensado como anestesia tornou-se estesia. A arte de maneira geral e mais especificamente o cinema operam contemporaneamente um "contínuo exercício de desorientação" (Favaretto, 2015, p. 13) que interrompe os fluxos cotidianos e 
abre janelas para realidades que vão muito além das experiências concretas a que estamos limitados. Disso resulta o caráter edu- cativo do cinema, como "articulação entre o real que lhe ultrapassa e o interior de quem o vê" (Almeida, 2017, p. 14).

\section{BIBLIOGRAFIA}

ABBAgnANO, N. Dicionário de filosofia. São Paulo, Martins Fontes, 2007.

ALMEIDA, Rogério de. "O processo de criação literária pensado pelo cinema de François Ozon: análise de dois filmes", in Lúcia Leão (org.). Processos do imaginário. São Paulo, Képos, 2016.

"Cinema e educação: fundamentos e perspectivas", in Educação em Revista,

v. $33,2017$.

"O pensamento trágico de Clément Rosset", in Revista Trágica, v. 12, n.1, 2019.

Disponível em: https://revistas.ufrj.br/index.php/tragica/article/view/27226/14839.

BORDWELL, David. La narración en el cine de ficción. Barcelona/Buenos Aires/Cidade do México, Paidós, 1996.

CASSIRER, Ernst. Ensaio sobre o homem: introdução a uma filosofia da cultura humana.

São Paulo, Martins Fontes, 1994.

DELEUZE, Gilles. Nietzsche e a filosofia. Rio de Janeiro, Editora Rio, 1976.

DURAND, Gilbert. A imaginação simbólica. São Paulo, Cultrix/Edusp, 1988. L'imaginaire. Essai sur les sciences et la philosophie de l'image. Paris, Hatier, 1994. As estruturas antropológicas do imaginário. São Paulo, Martins Fontes, 1997.

FAVARETTO, Celso. "O entrelugar da arte contemporânea", in Marcelo Carvalho; Bruno Guimarães. Estética e arte. São Paulo, Anpof, 2015, pp. 9-23.

GIACOIA JUNIOR, Oswaldo. Nietzsche: o humano como memória e como promessa.

Petrópolis, Vozes, 2014.

JAKOBSON, Roman. "Aspectos linguísticos da tradução", in Linguística e comunicação.

São Paulo, Cultrix, 2003.

MORIN, Edgar. O cinema ou o homem imaginário: ensaio de antropologia sociológica.

São Paulo, É Realizações, 2014.

NIETZSCHE, Friedrich. Obras incompletas. São Paulo, Abril Cultural, 1983. Genealogia da moral. São Paulo, Companhia das Letras, 1998.

ROSSET, Clément. A lógica do pior: elementos para uma filosofia trágica. Rio de Janeiro,

Espaço e Tempo, 1989. Le réel: traité de l'idiotie. Paris, Les Éditions de Minuit, 2004. O real e seu duplo: ensaio sobre a ilusão. Rio de Janeiro, José Olympio, 2008.

RUIZ, Raúl. Poética del cine. Chile, Editorial Sudamericana, 2000.

STEINER, George. Gramáticas da criação. Rio de Janeiro, Globo, 2003.

Depois de Babel: questões de linguagem e tradução. Curitiba, Editora da UFPR, 2005.

WALTON, Kendal. "Temores Fictícios", in F. P. Ramos. Teoria contemporânea do cinema:

pós-estruturalismo e filosofia analítica. Vol. 1. São Paulo, Senac, 2005.

WITTGENSTEIN, Ludwig. Investigações filosóficas. São Paulo, Nova Cultural, 1999. 